\title{
From precautionary principle to risk-risk analysis
}

\author{
Indur M. Goklany
}

Both proponents and opponents of the precautionary principle have often argued that it substitutes for risk analysis. The principle itself received a ringing endorsement when The New York Times Magazine's year-end review of the best ideas of 2001 hailed it as "revolutionary," suggesting that it offered a superior approach to managing potential risks associated with new technologies (or actions or policies) than the risk-analysis paradigm currently employed by US society and the World Trade Organization $^{1}$. On the other hand, opposition to the precautionary principle has coalesced around precisely the point that it seems to reject the risk-analysis approach ${ }^{2}$. But I would argue that to take the precautionary principle seriously means we must, in fact, employ not just risk analysis, but risk-risk analysis.

Although there is no single definition of the precautionary principle, all its formulations call for reducing, if not eliminating, risks to public health, the environment, or both ${ }^{3}$. One popular formulation is the socalled Wingspread Declaration: "When an activity raises threats of harm to human health or the environment, precautionary measures should be taken, even if some cause-and-effect relationships are not established scientifically"4.

Taking the precautionary principle at face value means that when, or if, it is applied, the objective ought to be to ensure that the outcome of an action is at least "risk-neutral": that is, it should not cause environmental and public health risks to increase. And if the precautionary principle is used to choose between different technological or policy options, its application should favor the one that reduces overall risks the most.

This objective is easily met if a policy only reduces risks. In this case, clearly we should adopt the policy. Similarly, if a policy only increases risks, the decision is equally simple: avoid the policy. But most policy options reduce some public health and environmental risks while increasing or prolonging others ${ }^{3}$. Cases in point include policies that would foreswear the use of either genetically modified (GM) crops or dichlorodiphenyl trichloroethane (DDT).

Indur M. Goklany is a manager with the US Department of the Interior's Office of Policy Analysis. Views expressed here are his alone and not necessarily those of any unit of the US government (Igoklany@ios.doi.gov).
What do we do in such ambiguous situations? To ensure that a policy is truly precautionary - that is, reduces net risks or is riskneutral-one should compare the risks of adopting the policy against the risks of not adopting it (or the risks of the default policy). This inevitably forces us into risk-risk analysis. Thus, despite claims that risk analysis differs from, or is incompatible with, the precautionary principle, the latter logically ends up with risk-risk assessment.

Unfortunately, none of the versions of the precautionary principle provides any guidance on how it should be applied if a policy might be foreseen to lead to both positive and negative outcomes where, moreover, both sets of outcomes are uncertain. Accordingly, I have proposed a framework for employing the precautionary principle in such ambiguous situations based on a set of commonsense criteria that allow risks to be ranked and compared based on their nature, severity, magnitude, certainty, immediacy, irreversiblility, and other characteristics ${ }^{3}$. For instance, all else being equal, the immediacy criterion gives greater weight to threats that are more immediate, the uncertainty criterion to threats that are more certain, the expectation value criterion to those that are larger, and the adaptation criterion to those that are more difficult or costly to cope with ${ }^{3}$.

One criterion, however, relies more on ethics than common sense. This is the twopart public health criterion. The first part, the human mortality criterion, essentially holds that the risk of death to a human being outweighs similar risks to members of other species, regardless of the species. The second part, the human morbidity criterion, is less absolute ${ }^{3}$.

Remarkably, with or without this (unapologetically) anthropocentric criterion, applying this framework to evaluate whether a global ban on GM crops would indeed be precautionary leads the conclusion that a ban would, in fact, increase net risks to both global public health and the global environment. Thus, any version of the precautionary principle should actually require the use of GM crops, provided due caution is exercised before commercialization of individual GM crops ${ }^{3}$. This result contradicts conventional environmental wisdom.

To appreciate the why and wherefore of this result with respect to public health, consider that 800 million people worldwide suffer from hunger and undernourishment, and over 2 billion from malnutrition. As a result, hunger and malnutrition kill over 5 million children annually worldwide. In addition, poor nutritional habits are significant contributors to diseases of affluence (heart disease, strokes, and cancers), which kill almost 20 million more $^{3}$. To reduce the future toll of hunger, malnutrition, and poor nutritional habits, despite the almost inevitable future increase in human population, means that the quantity and nutritional quality of food must be enhanced. The faster this occurs, the fewer casualties there will be. And GM crops should increase the quantity and nutritional quality of food supplies faster than conventional crops.

Thus, a GM crop ban would retard reductions in global hunger, malnutrition, and diseases of affluence. On the other side of the ledger, the health effects of ingesting GM crops, if any, are not only much more uncertain, they are not now-and unlikely to be in the future-comparable in magnitude to the global toll from hunger and malnutrition. Therefore, a GM crop ban is likely to increase net harm to public health, condemning large numbers to premature death ${ }^{3}$.

With respect to environmental risks, consider that conventional agriculture, with its enormous demands for land, water, pesticides, and fertilizers, is the major stress on global biodiversity, and a significant source of greenhouse gases ${ }^{3}$. These environmental pressures can be reduced or contained more rapidly (and more certainly) with GM crops than with only conventional crops because the former are more likely to increase agriculture productivity (in terms of land and water) and to do so faster and with fewer or less toxic chemicals.

In summary, to be true to itself, the precautionary approach requires risk-risk analysis. This suggests an alternative formulation for the principle: "Public health and environmental policies should attempt to minimize net risks to public health and the environment based on the best available scientific information and their net anticipated costs to society". Or, more succinctly: "All things considered, thou shalt attempt to minimize net risks".

\footnotetext{
1. Pollan, M. New York Times Sunday Magazine 9 May (2001), 92, 94.

2. Miller, H. \& Conko, G. Nature Biotechnology 18, 697 (2000)

3. Goklany, I.M. The Precautionary Principle: A Critical Appraisal of Environmental Risk Assessment (Cato Institute, Washington, DC, 2001).

4. Raffensperger, C. \& Tickner, J., (eds.). p. 8 in Protecting Public Health \& the Environment: Implementing the Precautionary Principle (Island Press, Washington, DC; 1999).
} 